\title{
Pycnodysostosis with Multi-Segmental Spinal Canal Stenosis due to Ossification of the Yellow Ligament
}

\author{
Keiji Wada, Koichi Kanaya, Yasuaki Murata, Yoshiharu Kato \\ Department of Orthopaedics, Tokyo Women's Medical University, Tokyo, Japan
}

\begin{abstract}
Pycnodysostosis is an autosomal recessive disorder characterized by osteosclerosis, small stature, acro-osteolysis of the distal phalanges, loss of the mandibular angle, separated cranial sutures with open fontanels, and frequent fractures. One identified cause of the disease is reduced activity of the cysteine protease cathepsin K. A 48-year-old woman with a history of frequent fractures presented with a severe gait disturbance. Radiography, computed tomography, magnetic resonance imaging, and gene analysis were performed. Physical examination revealed open fontanels, and radiographs showed increased bone density. DNA sequence analysis revealed a deletion mutation of the cathepsin $\mathrm{K}$ gene. We diagnosed pycnodysostosis based on these findings. The magnetic resonance and computed tomography images demonstrated multilevel spinal canal stenosis due to ossification of the yellow ligament. We performed a laminectomy, and the patient's neurological signs and symptoms improved. To our knowledge, this is the first case of pycnodysostosis with ossification of the yellow ligament.
\end{abstract}

Keywords: Pycnodysostosis; Ossification of yellow ligament; Cathepsin K

\section{Introduction}

Pycnodysostosis is an autosomal recessive disorder characterized by osteosclerosis, small stature, acro-osteolysis of the distal phalanges, loss of the mandibular angle, separated cranial sutures with open fontanels, and frequent fractures $[1,2]$. One identified cause of the disease is reduced activity of the cysteine protease cathepsin $\mathrm{K}[2,3]$. Here, we report a case of pycnodysostosis with ossification of the yellow ligament (OYL) in the lower thoracic and upper lumbar spine. We also identified a mutation in the cathepsin $\mathrm{K}$ gene. The patient provided informed consent for publication of data concerning this case.

\section{Case Report}

A 48-year-old woman presented to our hospital with severe gait disturbance. She had a two year history of left leg numbness, and her gait had gradually deteriorated over the 6 months prior to presentation. On neurologic exam, deep tendon reflexes in both legs were markedly increased. Manual muscle testing revealed generalized weakness (Grade 4 of 5) throughout the lower extremities. Sensation was impaired below the T8 level. She also was experiencing urinary incontinence and was hardly able to walk due to severe spasticity of the lower extremities. Based on the neurological findings, we concluded that she had a myelopathy below the T8 level.

Received Jul 8, 2014; Revised Jul 8, 2014; Accepted Jul 26, 2014

Corresponding author: Keiji Wada

Department of Orthopaedics, Tokyo Women's Medical University,

8-1 Kawadacho, Shinjuku-ku, Tokyo 162-8666, Japan

Tel: +81-3-3353-8111; Fax:+81-3-3354-7360,E-mail:keijiwadajp@yahoo.co.jp 
Plain radiographs of the spine showed multilevel OYL in the lower thoracic and upper lumbar spine and spondylolysis in L4 and L5 vertebrae (Fig. 1). Magnetic resonance imaging (MRI) showed mild spinal canal stenosis at $\mathrm{T} 7 / 8, \mathrm{~T} 10 / 11$, and $\mathrm{T} 11 / 12$, and severe stenosis at T8/9, T9/10, and L1/2 (Fig. 2). Computed tomography
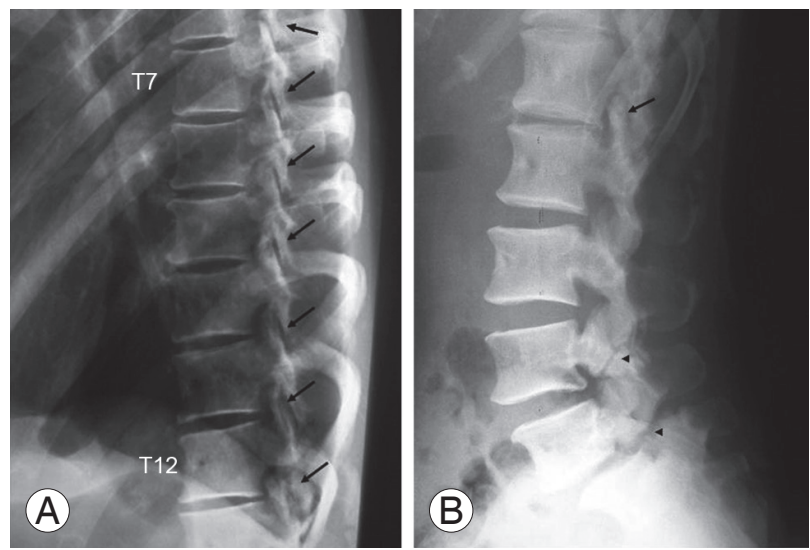

Fig. 1. Lateral radiographs of the thoracic $(\mathbf{A})$ and lumbar $(\mathbf{B})$ spine show ossification of the yellow ligament at T6/7, T7/8, T8/9, T9/10, $\mathrm{T} 10 / 11, \mathrm{~T} 11 / 12$, and L1/2 (arrows), and spondylolysis at L4 and L5 (arrow heads).

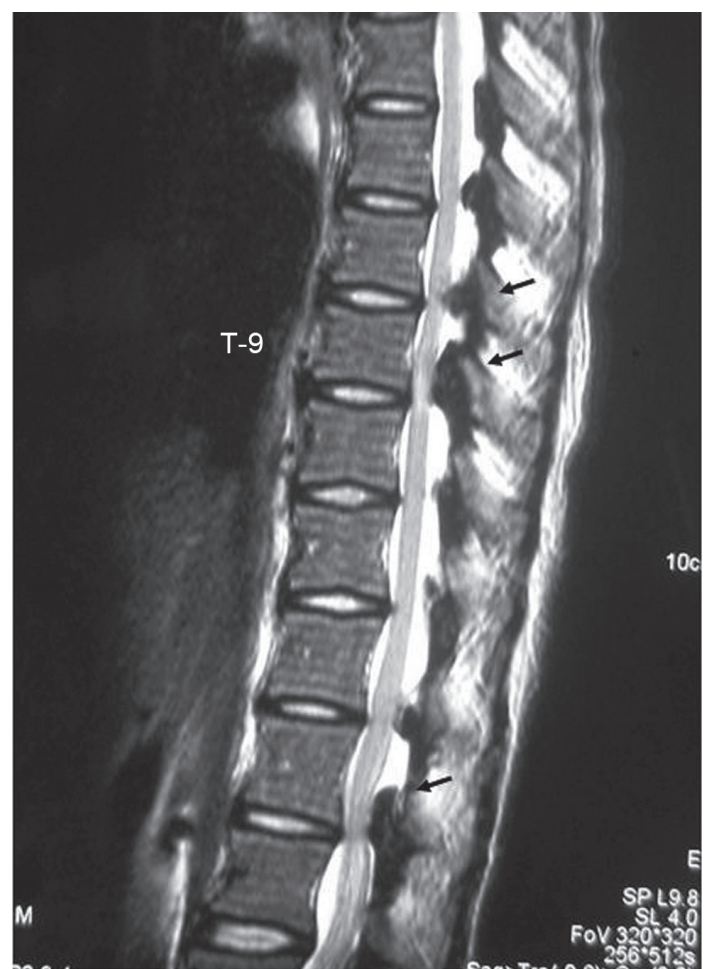

Fig. 2. Sagittal T2-weighted magnetic resonance imaging shows multilevel spinal canal stenosis at $\mathrm{T} 6 / 7, \mathrm{~T} 7 / 8, \mathrm{~T} 8 / \mathrm{g}$, $\mathrm{T} 9 / 10, T 10 / 11, T 11 / 12$, and $L 1 / 2$. The stenosis at $T 8 / 9$, $\mathrm{T} 9 / 10$, and $\mathrm{L} 1 / 2$ is severe (arrows). clearly showed OYL at these levels (Fig. 3). We concluded that her gait disturbance and urinary incontinence were caused by thoracic and lumbar spinal canal stenosis due to OYL.

Although she had several common features of pycnodysostosis, such as frequent lower leg fractures, separated cranial sutures with open fontanels, and high bone density on radiographs, pycnodysostosis had not been diagnosed previously. Since cathepsin K gene mutations have been reported as a cause of pycnodysostosis [3-7], a DNA sequence analysis of the gene was performed. As shown in Fig. 4A, revealing a deletion of the genomic DNA nucleotide $426 \mathrm{~T}$ in exon 5. This mutation caused a frame shift at amino acid 142 (Fig. 4B), resulting in a stop codon at amino acid 160 . This mutation is identical to that described in a report by Yamagiwa et al. [8] Based on this result, we diagnosed pycnodysostosis with a cathepsin $\mathrm{K}$ gene mutation.

Surgery was performed while evoked spinal cord potentials were monitored. Because the MRI revealed severe spinal cord compression due to OYL at T8/9, T12/L1, and $\mathrm{L} 1 / 2$ we chose to perform a total laminectomy at T8, T9,

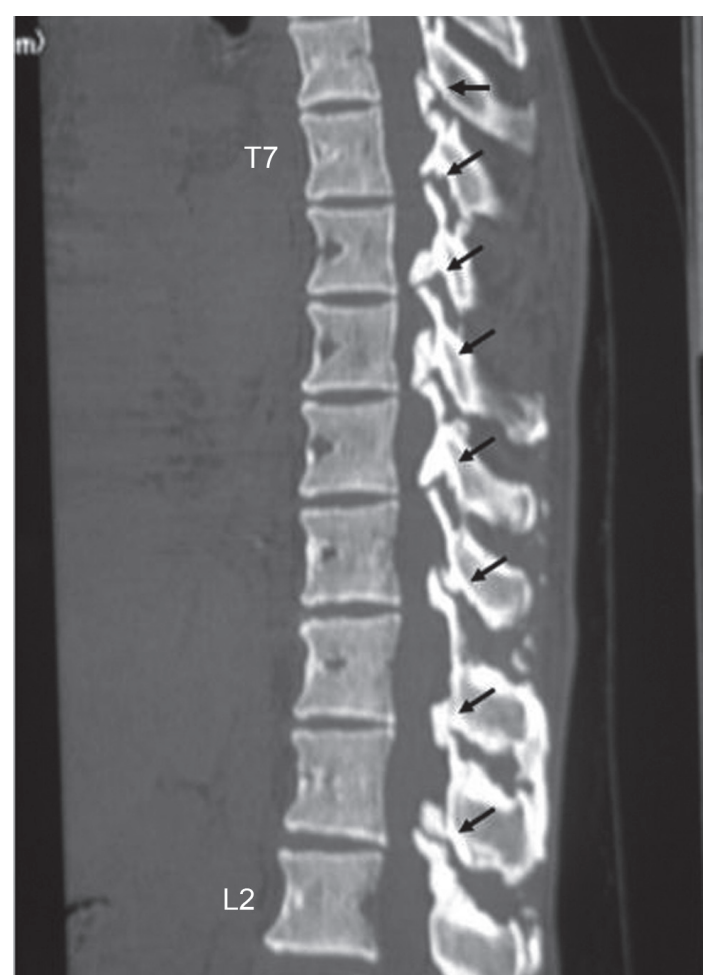

Fig. 3. Computed tomography clearly shows ossification of the yellow ligament at T6/7, T7/8, T8/9, T9/10, T10/11, $\mathrm{T} 11 / 12, \mathrm{~T} 12 / \mathrm{L} 1$, and L1/2 (arrows). 


\section{Cathepsin $\mathrm{K}$ exon 5}

Nucleotide change

\begin{tabular}{|c|c|}
\hline Nucleotide No. (S79895) $\rightarrow$ & 426 \\
\hline Wild type allele & 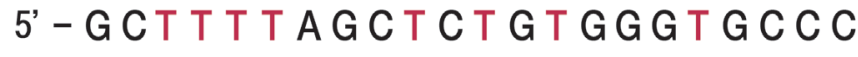 \\
\hline D-136 allele & $5^{\prime}-\mathrm{GCT}$ T T - A G C T C T G T G G G T G C C C \\
\hline Del $\rightarrow$ & 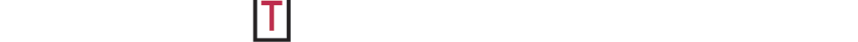 \\
\hline
\end{tabular}

Sequence chart \& Amino acid change

$\begin{array}{rrrrrrrr}\text { codon } \rightarrow & 141 & 142 & 143 & 144 & 145 & 146 & 147 \\ \text { Wild type allele } & \text { Ala } & \text { Phe } & \text { Ser } & \text { Ser } & \text { Val } & \text { Gly } & \text { Ala } \\ & 5 & \text { 5 } & \text { G C C T T T A G C T C T G T G G G T G C C C }\end{array}$

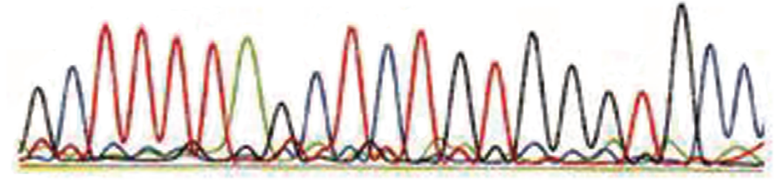

$\begin{array}{ccccccc}\text { codon } \rightarrow & 141 & 142 & 143 & 144 & 145 & 146 \\ \text { D-136 allele } & \text { Ala } & \text { Leu } & \text { Ala } & \text { Leu } & \text { Trp } & \text { Val } \\ & 5\end{array}-$ G C T T T A G C T C T G T G G G T G

(B)

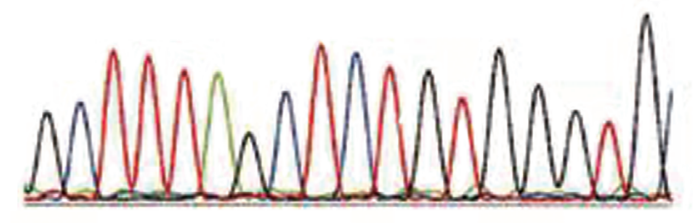

Fig. 4. (A) The results of DNA sequence analysis show a deletion of the genomic DNA nucleotide 426T. (B) This mutation causes a stop codon at amino acid 160.

and L1 and a partial laminectomy at T10/11 and T11/12.

Postoperatively, she was able to walk with a walker at three weeks, and with a Lofstrand crutch after three years.

\section{Discussion}

Spinal disorders in pycnodysostosis have been described in several reports. These include spondylolysis and other deformities, as reported by Beguiristain et al. $[1,9,10]$. To our knowledge, there have been no reports of pycnodys- ostosis with OYL. Ossification of the spinal ligaments, such as ossification of the posterior longitudinal ligament (OPLL) and OYL are common in Japan and throughout Asia [11,12]. These sometimes compress the spinal cord and cauda equina, leading to various neurological disorders, from myelopathy to cauda equina syndrome. The mechanisms causing ligament ossification have been extensively researched [12]. The involvement of many growth factors and cytokines, including bone morphogenic proteins and transforming growth factor- $\beta$, have 
been demonstrated in various histochemical and cytochemical analyses of ossified ligaments. Gene analysis studies have identified specific polymorphisms in several collagen genes, including type VI and XI collagens, that may be associated with OPLL $[11,12]$. In addition, several transcription factors regulating cellular differentiation may play an important role $[11,12]$. The exact mechanism, however, remains unclear.

In our patient, multilevel OYL was formed in pycnodysostosis leading to a severe gait disturbance. In vitro experiments have shown that ligament cells from patients with OPLL have some osteoblastic function [12]. In addition, mineral apposition and bone formation rates are increased in cathepsin K-deficient mice [7,13]. Based on these reports, we hypothesize that multilevel OYL can develop in pycnodysostosis by the following mechanism: a cathepsin K deficiency could lead to increased production of bone growth factors, which promote ossification of the spinal ligament by ligament cells with osteoblastic features.

This report demonstrates the OYL can develop in patients with pycnodysostosis and that treatment by laminectomy may relieve associated neurological problems. To supplement this initial case report, further studies are required to determine whether patients with pycnodysostosis have an increased risk of developing spinal ligament ossification.

\section{Conflicts of Interest}

No potential conflict of interest relevant to this article was reported.

\section{References}

1. Edelson JG, Obad S, Geiger R, et al. Pycnodysostosis. Orthopedic aspects with a description of 14 new cases. Clin Orthop Relat Res 1992;(280):263-76.

2. Motyckova G, Fisher DE. Pycnodysostosis: role and regulation of cathepsin $\mathrm{K}$ in osteoclast function and human disease. Curr Mol Med 2002;2:407-21.

3. Gelb BD, Shi GP, Chapman HA, et al. Pycnodysostosis, a lysosomal disease caused by cathepsin K deficiency. Science 1996;273:1236-8.

4. Hou WS, Bromme D, Zhao Y, et al. Characterization of novel cathepsin $\mathrm{K}$ mutations in the pro and mature polypeptide regions causing pycnodysostosis. J Clin Invest 1999;103:731-8.

5. Fujita Y, Nakata K, Yasui N, et al. Novel mutations of the cathepsin $\mathrm{K}$ gene in patients with pycnodysostosis and their characterization. J Clin Endocrinol Metab 2000;85:425-31.

6. Fratzl-Zelman N, Valenta A, Roschger P, et al. Decreased bone turnover and deterioration of bone structure in two cases of pycnodysostosis. J Clin Endocrinol Metab 2004;89:1538-47.

7. Schilling AF, Mulhausen C, Lehmann W, et al. High bone mineral density in pycnodysostotic patients with a novel mutation in the propeptide of cathepsin K. Osteoporos Int 2007;18:659-69.

8. Yamagiwa H, Asaoka M, Kato H, et al. Pycnodysostosis with a cathepsin K mutation: a case report. Acta Biol Med Ger 2001;49:31-7.

9. Beguiristain JL, Arriola FJ, Leyes M. Lumbar spine anomalies in a pycnodysostosis case. Eur Spine J 1995;4:320-1.

10. Zenke MS, Hatori M, Tago S, et al. Pycnodysostosis associated with spondylolysis. Arch Orthop Trauma Surg 2002;122:248-50.

11. Sarzi-Puttini P, Atzeni F. New developments in our understanding of DISH (diffuse idiopathic skeletal hyperostosis). Curr Opin Rheumatol 2004;16:287-92.

12. Inamasu J, Guiot BH, Sachs DC. Ossification of the posterior longitudinal ligament: an update on its biology, epidemiology, and natural history. Neurosurgery 2006;58:1027-39.

13. Li CY, Jepsen KJ, Majeska RJ, et al. Mice lacking cathepsin $\mathrm{K}$ maintain bone remodeling but develop bone fragility despite high bone mass. J Bone Miner Res 2006;21:865-75. 